\author{
I E A Institute of \\ YK Business Administration \\ 页下 \\ Karachi \\ Leadership and Ideas for Tomorrow
}

Article 5

Volume 16 Issue 1

January-June 2021

\section{Business Review}

\title{
$1-1-2021$
}

\section{Volatility spillover between stock market and currency market of Pakistan in the presence of structural breaks}

\author{
Muhammad Jamil \\ Jammu \& Kashmir, Muzaffarabad, Pakistan \\ Hifsa Mobeen \\ Pakistan Institute of Development Economics, Islamabad
}

Ghulam Ishaq Khan Memorial Chair (SBP), Kashmir Institute of Economics, The University of Azad

Follow this and additional works at: https://ir.iba.edu.pk/businessreview

Part of the Business Administration, Management, and Operations Commons, Econometrics Commons, Finance Commons, Finance and Financial Management Commons, Management Sciences and Quantitative Methods Commons, and the Organizational Behavior and Theory Commons

\section{(c) (1)}

This work is licensed under a Creative Commons Attribution 4.0 International License.

\section{Recommended Citation}

Jamil, M., \& Mobeen, H. (2021). Volatility spillover between stock market and currency market of Pakistan in the presence of structural breaks. Business Review, 16(1), 1-12. Retrieved from https://doi.org/ 10.54784/1990-6587.1377

This article is brought to you by iRepository for open access under the Creative Commons Attribution 4.0 License and is available at https://ir.iba.edu.pk/businessreview/vol16/iss1/5. For more information, please contact irepository@iba.edu.pk. 


\title{
Volatility spillover between stock market and currency market of Pakistan in the presence of structural breaks
}

\author{
Muhammad Jamil · Hifsa Mobeen
}

\begin{abstract}
This study examines the volatility transmission between the currency market and the stock market of Pakistan in the presence of structural breaks. For this purpose, daily data from the stock market and currency market is analyzed. An empirical investigation is conducted using the bivariate EGARCH model and the test for multiple structural breaks developed by Bai and Perron (2003). This study analyses these markets with the inclusion of sudden changes. Results of the EGARCH model suggest that volatility spillover is positive and bidirectional between these markets of Pakistan.
\end{abstract}

Keywords Volatility spillover · Bai and Perron test · EGARCH Model

\section{Introduction}

Over the last few decades, volatility in financial markets has been the subject matter of many researches in the world. Increasing integration among major financial markets has brought the attention and focus of academics, researchers, and policymakers towards volatility modeling and analyzing the volatility transmission mechanism among major international financial markets. Volatility, in literature, is defined as 'fickleness, instability, or uncertainty' whether appearing in risk management, asset pricing, or portfolio optimization (Jamil 2011). Due to globalization and the financial liberalization of world markets, the volatility of a certain market may lead to instability or uncertainty in other related markets. This is referred to as volatility spillover (Mishra et al 2010). Facts and figures of volatility and volatility spillover among financial markets provide a huge help for making economic and financial decisions.

After financial sector reforms in 1990, the financial markets of Pakistan

Muhammad Jamil

University of Azad Jammu \& Kashmir-Pakistan

E-mail: m.jamil@ajku.edu.pk

Hifsa Mobeen

Pakistan Institute of Development Economics-Pakistan

(C)Jamil, M. and Mobeen, H. 2021 
have become more interdependent. Zapatero (1995) argued that in perfectly integrated and interdependent financial markets, explicit linkages always exist among the volatility of markets. Due to these explicit inter-market linkages, the exchange rate has become more responsive to innovations in the stock market (Yang and Doong 2004). Tranquil periods are usually followed by moderately high instability periods. Political and economic happenings can cause unexpected changes in the volatility of financial assets' prices and returns in such circumstances. An in-depth understanding of volatility and volatility transmission between financial markets in the presence of economic, political, and financial events has huge implications for stability of financial markets.

Because of uncertainty in financial markets and frequent portfolio switching by investors, instability in one market may travel to other related markets very easily. Keeping in mind the implications of inter-market linkages, this study intended to analyze the research hypothesis that the volatility spillover between the currency market and the stock market is bidirectional. Numerous studies, on the subject matter, have been conducted in literature both in the context of Pakistan as well as for other regions of the world. However, none has investigated the volatility spillover by endogenously detecting structural breaks. The novelty of the present study in the context of Pakistan is that it analyzes the volatility spillover between stock and currency markets in the presence of endogenously detected structural breaks.

The rest of the study is divided into four sections. Section 2 provides a literature review. Section 3 outlines the methodology and data collection process. Results are discussed in detail in section 4 and section 5 provides the conclusion of the study.

\section{Literature review}

Theoretical links between exchange rate and stock prices can be explained through the Flow Oriented model and Stock Oriented model. Dornbusch and Fischer (1980) developed the Flow Oriented model which suggests that the exchange rate has a positive impact on stock prices and causality runs from the exchange rate to stock prices. On the other hand, according to the Stock Oriented model proposed by Branson (1983) causality runs from stock prices to exchange rate and there is a positive relationship between exchange rates and stock prices. According to both the flow-oriented and stock-oriented models, a positive relationship exists between exchange rate and stock prices, which depicts that both currency and stock markets are interlinked. The inter-linkage of both markets means that, if returns' volatility of the stock market (currency market) increases due to any external or internal shock it will induce volatility in the currency market (stock market) returns as well.

The importance of the role of structural breaks for the estimation of volatility persistence was first identified and analyzed by Lamoureux and Lastrapes (1990). The authors applied the GARCH model augmented with structural breaks dummy variables to compare and analyze the role of structural breaks in volatility persistence. For this purpose, daily data of 30 commonly traded 
stocks was selected from the New York Exchange. The results of the study reported that for most of the stocks, GARCH model parameters are close to 1 in the case of a simple GARCH model. However, when structural breaks are incorporated in the GARCH model, the magnitude of volatility persistence decreases considerably. Similar outcomes were conveyed by Aggarwal et al (1999) for stock returns of six developed and ten emerging markets and Hammoudeh and Li (2008) for GCC countries, using similar methodology.

Variation in volatility transmission due to financial liberalization, in the stock market of India, is analyzed by Batra (2004) using monthly data. A comparison is made between the naive EGARCH model and the EGARCH model adjusted for structural changes. Structural changes are determined by using the test for multiple structural breakpoints developed by Bai and Perron (2003). Results of the model report that when structural changes are ignored, the magnitude of volatility transmission estimated through a simple EGARCH model is high, relative to the model in which structural changes are taken care of. Information transmission across the large-cap and small-cap portfolios is investigated by Marcelo et al. (2008) for the Spanish stock market. Sudden change points in unconditional variances are detected by the ICSS algorithm. The authors applied the regime-switching EGARCH model by utilizing weekly data. The results of the study reported that there exists information transmission and volatility spillover among small-cap and large-cap portfolios. Similar effects have been reported by Kasman (2009). This study is conducted by employing a similar methodology with a simple GARCH model for the BRIC countries.

Volatility transmission across stock index futures markets of the US, UK, and Japan was explored by Huang (2012). ICSS algorithm accompanied by the bivariate GARCH model is estimated and analyzed by the author. The study postulates that there exists bidirectional volatility spillover across UK and US stock index futures markets. The same phenomenon is explored by Zivkov et al (2015) for four Eastern European countries. To test the bidirectional volatility spillover effect in the presence of structural breaks, the Fractionally Integrated Autoregressive Conditional Heteroskedastic (FIARCH) model is applied. Using the ICSS algorithm, structural breaks are identified. The study suggests that more volatility flows from the stock market to the exchange rate market if structural breaks are considered.

Yeshan and Prabhath (2017) studied the phenomenon of volatility spillover in South Asian economies. GARCH-BEKK model has been employed for analysis. The results of the study suggest the existence of bilateral volatility spillover. Iqbal et al (2020) worked on similar phenomena and regions of analysis. EGARCH model was used over the data period from July 2002 to June 2016. However, this study selected only one structural break (financial crisis 2008) exogenously. The study postulates a remarkable volatility spillover after the structural break. Furthermore, Aziz et al (2020) investigated the volatility spillover among equity and commodity markets using the GARCH model. Monthly data from 2005 to 2016 was used. The results suggested that there is no volatility spillover among the two markets in the absence of structural breaks. 


\section{Methodology and data description}

Nelson (1991) has introduced an extension of the GARCH model called the EGARCH model. Literature highlights that the EGARCH model is more advantageous than other members of $\mathrm{ARCH} / \mathrm{GARCH}$ family models when the objective is to analyze volatility spillover assuming Constant Conditional Correlation $(\mathrm{CCC})$.

For calculating returns' volatility, $\operatorname{AR}(\mathrm{k})-\operatorname{EGARCH}(\mathrm{p}, \mathrm{q})$ model can be stated as follows:

$$
\begin{gathered}
R_{t}^{x}=\alpha_{0}+\alpha_{1} \sum_{i=1}^{n} R_{t-i}^{x}+e_{t} \text { where } e_{t} \sim\left(0, \sigma^{2}\right) \\
\log \left(h_{t}^{x}\right)=\omega+\sum_{j=1}^{p} \gamma_{j} \log h_{t-j}^{x}+\sum_{j=1}^{q} \rho_{j}\left|\frac{\mu_{t-j}}{\sqrt{h_{t-j}}}\right|+\sum_{m=1}^{r} \theta_{m} \frac{\mu_{t-m}}{\sqrt{h_{t-m}}}
\end{gathered}
$$

The above two equations represent the $\mathrm{AR}(\mathrm{k})-\mathrm{EGARCH}(\mathrm{p}, \mathrm{q})$ model. In equation $1 R_{t}^{x}$ represent returns of variable $x$ at time $t$ where $t=1,2, . ., T . R_{t-i}^{x}$ is the previous period returns of variable $x$ where, $\mathrm{i}=1,2, \ldots, \mathrm{n}$. Variable $x$ represents the data series of $R K S E$ and $R E X R$. In equation $2 \log \left(h_{t}^{x}\right)$ is the $\log$ of the variance of variable $x . \omega$ is the constant level of volatility. $\log h_{t-j}^{x}$ indicates that the leverage effect is not quadratic but exponential. Further, the predictions of the conditional variance are assumed to be non-negative without commanding any restrictions on the coefficients. The response of volatility to changes in the news is measured by the coefficient $\rho_{j}$. The relationship between the volatility and negative news and positive news is explained by the coefficient $\theta_{m}$. For the selection of appropriate orders of $n, p, q$ and $k$ in equation 1 and equation 2, Schwarz Bayesian Information Criteria (SBIC) is used.

\subsection{Bai and Perron multiple breaks points test}

Following the idea of Quandt (1958); Bai and Perron (2003) developed multiple breakpoints tests for discrete moves in unconditional variance. The date of breaks and number of breaks is determined by using the dynamic programming algorithm. The Bai and Perron test starts its working by looking for a single breakpoint, then searching for a second breakpoint, and so on. Optimal numbers of breakpoints are selected based on the lowest sum of the square of residuals. It detects a maximum of five numbers of breakpoints. This test determines structural breaks in a linear model regressed by the ordinary least square method. According to the test, structural breaks in returns series of variable $R K S E$ and $R E X R$ are determined by using the following equation:

$$
R_{t}^{x}=\alpha_{0}+\sum_{i=1}^{k} \alpha_{i} R_{t-i}^{x}+e_{t}
$$

$R_{t}^{x}$ is the returns series of variable $x(R K S E \& R E X R)$ on which breakpoint test is being applied, $\sum_{i=1}^{k} \alpha_{i} R_{t-i}^{x}$ represents the autoregressive terms of returns of 
variable $x$ where, $\mathrm{i}=1,2, \ldots, \mathrm{k}$. The order of autoregressive terms is selected based on the SBIC criterion.

\subsection{EGARCH model augmented with structural breaks}

To estimate the variance series of the variables with the effect of structural breaks, the corresponding $\operatorname{AR}(\mathrm{k})-\mathrm{EGARCH}(\mathrm{p}, \mathrm{q})$ model adjusted with breakpoints is as follows:

$$
\begin{gathered}
R_{t}^{x}=\alpha_{0}+\alpha_{1} R_{t-1}^{x}+\sum_{i=1}^{5} \tau_{i} D_{i}^{x}+e_{t} \text { where } e_{t} \sim\left(0, \sigma^{2}\right) \\
\log \left(h_{t}^{x}\right)=\omega+\sum_{i=1}^{p} \gamma_{j} \log h_{t-j}^{x}+\sum_{j=1}^{q} \rho_{j}\left|\frac{\mu_{t-j}}{\sqrt{h_{t-j}}}\right|+\sum_{m=1}^{r} \theta_{m} \frac{\mu_{t-m}}{\sqrt{h_{t-m}}}
\end{gathered}
$$

Equation 4 is the mean equation. In the mean equation $D_{i}^{x}$ represents dummy variables for structural breaks detected by Bai and Perron test in variable $x$ where, $\mathrm{i}=1,2, \ldots 5$. Variable $x$ can be any variable from the list of variables considered in this study. Equation 5 is representing the variance equation. Explanations of the remaining parameters of equations 4 and 5 are the same as discussed above for the equation 1 and 2 .

\subsection{EGARCH model for estimating volatility spillover}

After calculating the variance of variables with the effect of structural breaks, the phenomenon of volatility spillover between the stock market and currency market is captured by using the bivariate $\mathrm{AR}(\mathrm{k})$-EGARCH(p,q) model. Following Enders (2008), corresponding mean and variance equations used for estimating the volatility spillover are as follows:

$$
\begin{gathered}
R_{t}^{x}=\alpha_{0}+\alpha_{1} R_{t-1}^{x}+\beta_{1} R_{t-1}^{y}+e_{t} \text { where } e_{t} \sim\left(0, \sigma^{2}\right) \\
\log \left(h_{t}^{x}\right)=\omega+\sum_{i=1}^{p} \gamma_{j} \log h_{t-j}^{x}+\sum_{j=1}^{q} \rho_{j}\left|\frac{\mu_{t-j}}{\sqrt{h_{t-j}}}\right|+\sum_{m=1}^{r} \theta_{m} \frac{\mu_{t-m}}{\sqrt{h_{t-m}}}+\pi_{y} \log \left(h_{t}^{y}\right)
\end{gathered}
$$

Equation 6 is the mean equation. In the mean equation $R_{t-1}^{y}$ is representing autoregressive term of returns of variable $y$, where $y$ is the second variable from $R K S E$ and $R E X R$, for bivariate analysis. For example, in the mean equation, if $x$ is representing returns on the bilateral nominal exchange rate $(R E X R)$ then $y$ will be KSE-100 index returns (RKSE). Equation 7 is representing the variance equation. $\pi_{y} \log \left(h_{t}^{y}\right)$ is the returns' volatility of variable $y$ and $\pi_{y}$ is a volatility spillover parameter for volatility spillover from variable $y$ to variable $x$ i.e. from KSE-100 index returns' volatility ( $R K S E)$ to bilateral nominal exchange rate returns' volatility $(R E X R)$. Explanations of the remaining parameters of the equations 6 and 7 are the same as discussed for the equation 1 and 2.

Business Review: (2021) 16(1):1-12 


\subsection{Data}

Daily time series data comprising five trading days has been analyzed. Daily data sample spans from August 4, 1997, to August 31, 2016. KSE 100 index (KSE) representing the Karachi Stock Exchange market and bilateral nominal exchange rate, Pak-rupees in terms of US-Dollar (EXR) representing the currency market has been analyzed. Daily data on closing stock prices of the KSE-100 index has been collected from the Business Recorder, whereas daily data on the bilateral nominal exchange rate has been collected from the State Bank of Pakistan. Returns on the bilateral nominal exchange rate and stock prices are calculated as the first difference of logarithmic values of $L K S E$ and $L E X R$ respectively. Calculation of returns has been being done according to the following formula;

$$
R_{t}^{x}=\log \left(x_{t}\right)-\log \left(x_{t-1}\right)
$$

where, $R_{t}^{x}$ is returns at time $t$ of variable $x$, where $x$ represents the data series of variables $L K S E$ and $L E X R$. The subscript $t$ is used for time.

\section{Results and discussion}

Descriptive statistics of the growth rate of the bilateral nominal exchange rate $R E X R$ and KSE-100 index $R K S E$ are presented in table 1. The mean growth rate of all variables is positive and is closer to zero. The value of kurtosis is greater than the critical value i.e. 3, which corresponds to the fact highlighted by Mandelbrot (1963), suggesting that all data series have more extreme values and have greater volatility. Jarque-Bera statistics confirm that the distribution of the returns of all variables is normal.

The stock market is affected by countless factors. These factors might be

Table 1: Descriptive statistics

\begin{tabular}{lcc}
\hline Statistics & RKSE & REXR \\
\hline Mean & 0.001 & 0.000 \\
Median & 0.001 & 0.000 \\
Maximum & 0.128 & 0.083 \\
Minimum & -0.099 & -0.083 \\
Std Dev & 0.014 & 0.004 \\
Skewness & -0.389 & 1.004 \\
Kurtosis & 8.632 & 169.258 \\
Jark Bera & 6702.382 & 5733069.000 \\
(P-Value) & 0.000 & 0.000 \\
\hline
\end{tabular}

internal or external. Among external factors, the exchange rate remains dominant throughout history. Karachi stock exchange came into being soon after the independence of Pakistan to facilitate the trade of ordinary shares, redeemable certificates, and corporate bonds in the country. In 1998 market capitalization fell due to the nuclear test and economic sanctions. In 2002, the international magazine 'Business Week' pronounced KSE as the best performing market in 
the world because of high liquidity and improved management and administration. During the global financial crisis 2008, the KSE-100 index had declined slightly, however the overall performance of KSE remained least affected relative to the other Asian stock exchange markets.

During the period of Musharraf's rule, 1999 to 2007, the exchange rate
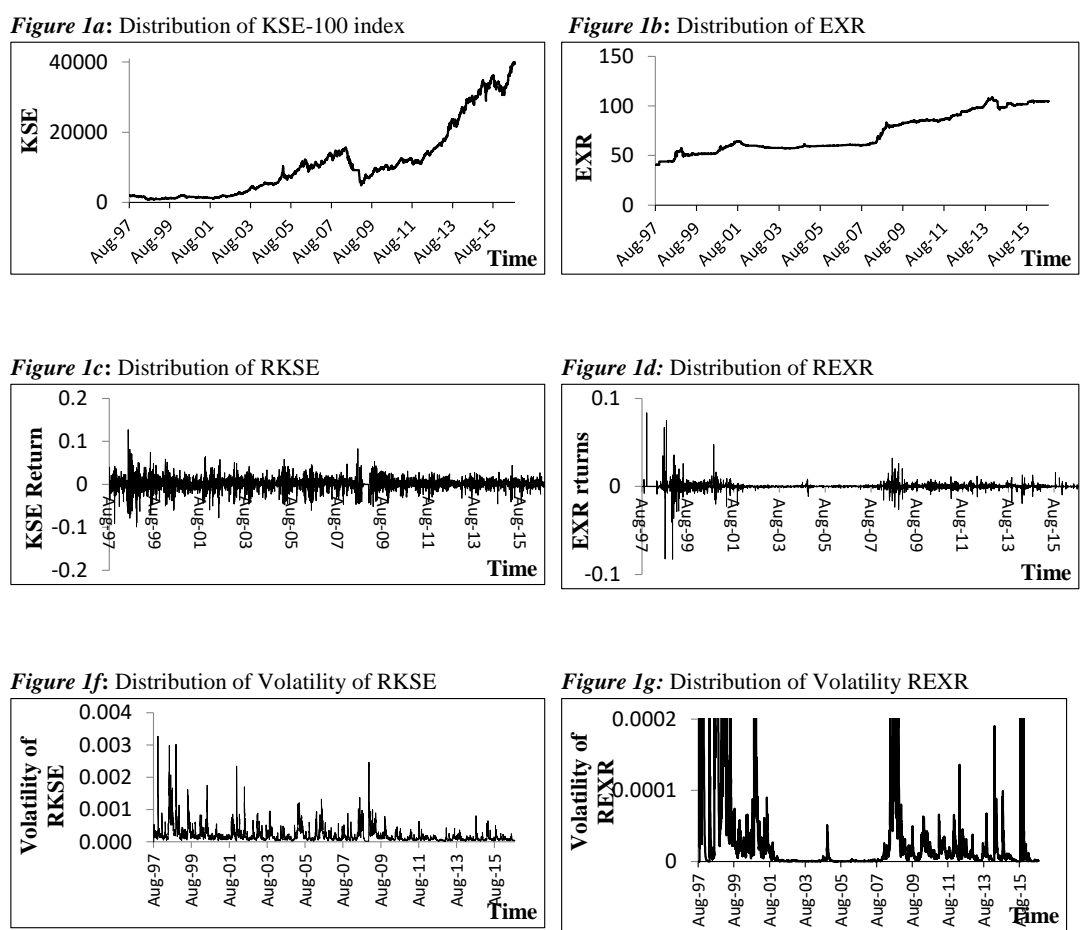

Fig. 1: Distribution and volatility of RKSE and REXR

remained stable to some extent. The reason for the stability of the exchange rate during that particular period was the heavy remittances inflow and foreign direct investment. In 2008, the foreign reserves of Pakistan decreased due to mounting oil prices, political instability and security issues in the country. During the period from 2014 to 2016 exchange rate remained almost stable.

Before checking the stationarity of the data, the lag order for all the variables is checked according to the SBIC. According to SBIC, lag order of $L K S E$ is significant till the second lag, and lag length of $L E X R$ and $L G P$ are significant till the third lag. However, the lag order of $L O P$ is significant at level. In the next step, to examine the stationarity of the data, Augmented Dickey-Fuller (ADF) and Philips Perron (PP) tests are being applied to each variable's data series included in the analysis. Results of these tests are presented in table 2.

According to ADF and PP test null hypothesis is accepted at level, indicating that $L K S E$ and $L E X R$ have a unit root at the level. However, the null hypothesis at the first difference is rejected for both data series by both tests, demonstrating that both variables' data series have no unit root at first differ-

Business Review: (2021) 16(1):1-12 
M. Jamil and H. Mobeen

Table 2: Results of unit root tests

\begin{tabular}{lccccc}
\hline \multirow{2}{*}{ Variables } & \multicolumn{2}{c}{ ADF-test } & \multicolumn{2}{c}{ PP-test } \\
\hline & Level & First difference & Level & First difference & Order of integration \\
\hline$L K S E$ & 0.131 & $-44.437^{* * *}$ & -0.039 & $-64.242^{* * *}$ & $\mathrm{I}(1)$ \\
$L E X R$ & -1.449 & $-43.478^{* * *}$ & -1.422 & $-68.275^{* * *}$ & $\mathrm{I}(1)$ \\
\hline
\end{tabular}

Note: Critical values at $1 \%, 5 \%$ and $10 \%$ significance level are $-3.431,-2.862$ and -2.567 , respectively whereas, ${ }^{* * *},{ }^{* *}$ and $*$ indicate significance at $1 \%, 5 \%$ and $10 \%$ level of significance, respectively.

ence. The stationarity of all data series at first difference implies that series are integrated of order one I(1). Further ARCH test is employed to check for the existence of issues of autocorrelation and heteroskedasticity in the RKSE and $R E X R$. For this purpose, the ARCH effect is checked by applying Breusch and Pagan test. The possible existence of the ARCH effect is confirmed by the resultant significant chi-square value. Hence, the EGARCH model can be applied successfully.

To test the structural breaks in the mean equation, Bai and Perron's multi-

Table 3: Results of Bai and Perron multiple structural breakpoints test

\begin{tabular}{lcccc}
\hline Variable & No. of breakpoints & Date of breakpoints & Obs No. & Breakpoint in mean \\
\hline \multirow{3}{*}{$R K S E$} & \multirow{3}{*}{3} & 36081 & 312 & YES \\
& & 39400 & 2683 & YES \\
& & 39840 & 2997 & YES \\
& \multirow{2}{*}{ REXR } & 36014 & 265 & YES \\
& & 36368 & 517 & YES \\
& & 36727 & 774 & YES \\
& 39741 & 2926 & YES \\
\hline
\end{tabular}

ple structural breaks point tests have been applied on returns series of KSE-100 index $R K S E$ and the bilateral nominal exchange rate returns $R E X R$. Corresponding results of Bai and Perron multiple structural breaks point tests are reported in table 3. In the mean of the KSE-100 index returns RKSE series, 3 structural breaks have been detected. Five structural breaks in the mean returns series of bilateral nominal exchange rate $R E X R$ have been reported by the Bai and Perron test.

Afterward dummy variables series are created for each structural break of each variable individually. Dummy variables series are created by putting 1 from the start of a break to onward and 0 elsewhere. Corresponding dummy variables series of each variable are placed in the mean equation of the EGARCH model and volatility is estimated with the inclusion of structural breaks in the mean equation of returns of each variable. Variance series with the effect of structural breaks are generated and then placed in the variance equation while estimating volatility transmission through the bivariate EGARCH model.

The results of the variance equation regarding volatility spillover are presented in table 4 . Results of volatility spillover from RKSE $\rightarrow$ REXR suggest 
Volatility spillover between stock market and currency market...

Table 4: Volatility spillover between stock and currency markets

\begin{tabular}{lcc}
\hline Coefficients & $\mathrm{KSE} \rightarrow \mathrm{EXR}$ & $\mathrm{EXR} \rightarrow \mathrm{KSE}$ \\
\hline$\omega$ & $-0.050^{* * *}$ & $-0.827^{* * *}$ \\
& $(-4.71)$ & $(-7.23)$ \\
$\gamma_{1}$ & $0.951^{* * *}$ & $0.912^{* * *}$ \\
& -628.26 & -7.35 \\
$\gamma_{2}$ & & 0.019 \\
& & -0.16 \\
$\rho_{1}$ & $0.646^{* * *}$ & $0.432^{* * *}$ \\
& -53.05 & -24.15 \\
$\rho_{2}$ & $-0.474^{* * *}$ & $-0.105^{* * *}$ \\
$\theta$ & $(-42.68)$ & $(-2.75)$ \\
& $0.014^{* *}$ & $-0.078^{* * *}$ \\
$\pi$ & -3.86 & $(-6.79)$ \\
& $0.068^{* * *}$ & $0.003^{*}$ \\
\hline SBIC & -39.66 & -1.94 \\
AR(k)-EGARCH(p, q) & AR(1)-EGARCH $(1,2)$ & -6.05 \\
\hline
\end{tabular}

Note: Values in parenthesis are $\mathrm{z}$-Values. Whereas, ${ }^{* * *},{ }^{* *}$, and $*$ indicate significance at $1 \%, 5 \%$, and $10 \%$ level of significance, respectively.

that the volatility spillover parameter $\pi$ is positive and highly significant. However, $\pi$ is positive and weakly significant in the case of volatility spillovers from REXR $\rightarrow$ RKSE. The extent of volatility spillover from RKSE $\rightarrow$ REXR is 0.068 , which is greater than the extent of volatility spillover from REXR $\rightarrow$ RKSE which is 0.003 . The sizes of volatility spillover between both the markets are significant and positive. However, if the magnitude of both pairs of markets is compared, it can be inferred that the stock market has a dominant role in transmitting volatility to the currency market relative to the opposite case. The reason might be frequent innovations in the stock market relative to the currency market. It implies that an increase in volatility of KSE-100 index returns (stock market) leads to an increase in volatility of bilateral nominal exchange rate returns (currency market). From the above-reported results, it can be concluded that there exist positive and significant bidirectional volatility spillovers between the currency market and the stock market. The same results are confirmed by Ewing and Malik (2005) for the US. To confirm the results, robust analysis is carried out. For this purpose out of the sample 168 observations are created through the moving average forecasting technique of time series econometrics.

\section{Conclusion}

Over the last few decades, financial market volatility has been the subject of many researches in the world. In the 1990s after the reforms of the financial sector of Pakistan, financial markets have become more interdependent. Zapatero (1995) argued that in perfectly integrated and interdependent financial markets, explicit linkages always exist among the volatility of markets.

Keeping in view the importance of these issues, the objective of this research

Business Review: (2021) 16(1):1-12 
study was to inspect the volatility spillover between the stock and currency markets of Pakistan. The hypothesis of the study is tested by applying the bivariate EGARCH model and Bai and Perron (2003) test on daily data of KSE-100 index returns' volatility and bilateral nominal exchange rate returns' volatility. According to the results provided by the EGARCH model, bidirectional positive volatility spillover exists between KSE-100 index returns volatility and bilateral nominal exchange rate returns' volatility.

The information set available through this study can be of great importance for investors, multinational firms, and policymakers. The policymakers can get benefit by understanding the markets' behavior to efficiently formulate and implement effective financial policies for financial and economic stability. Likewise, investors can manage their international portfolios by using the information set available through this study. Further, the results of this study can also help multinational companies to stabilize their earnings by managing their exposure to foreign contracts and currency risk.

For further research, it is recommended that analysis of volatility transmission should be done by using more comprehensive models. Regime switching models (like the MCMS model, SWARCH model, SWGARCH model, etc.) are more comprehensive models in which a variety of mechanisms of volatility transmission can be studied in detail. Moreover, some research can be extended for panel data analysis including Pakistan, as less body of literature is available in this regard.

\section{References}

Aggarwal R, Inclan C, Leal R (1999) Volatility in emerging stock markets. Journal of financial and Quantitative Analysis pp 33-55

Aziz T, Sadhwani R, Habibah U, Al Janabi MA (2020) Volatility spillover among equity and commodity markets. Sage Open 10(2):2158244020924,418

Bai J, Perron P (2003) Computation and analysis of multiple structural change models. Journal of applied econometrics 18(1):1-22

Batra A (2004) Stock return volatility patterns in india. Tech. rep., Working paper

Branson WH (1983) A model of exchange-rate determination with policy reaction: evidence from monthly data. NBER Working Paper (w1135)

Dornbusch R, Fischer S (1980) Exchange rates and the current account. The American Economic Review 70(5):960-971

Enders W (2008) Applied econometric time series. John Wiley \& Sons

Ewing BT, Malik F (2005) Re-examining the asymmetric predictability of conditional variances: The role of sudden changes in variance. Journal of Banking \& Finance 29(10):26552673

Hammoudeh S, Li H (2008) Sudden changes in volatility in emerging markets: The case of gulf arab stock markets. International Review of Financial Analysis 17(1):47-63

Huang PK (2012) Volatility transmission across stock index futures when there are structural changes in return variance. Applied Financial Economics 22(19):1603-1613

Iqbal HR, Saeed SK, Ali Shah SZ (2020) Structural breaks and volatility spillover in south asian economies. SEISENSE Journal of Management 3(1)

Jamil M (2011) Essays on financial markets volatility. PhD thesis, uniwien

Kasman A (2009) The impact of sudden changes on the persistence of volatility: Evidence from the bric countries. Applied Economics Letters 16(7):759-764

Lamoureux CG, Lastrapes WD (1990) Persistence in variance, structural change, and the garch model. Journal of Business \& Economic Statistics 8(2):225-234 
Mandelbrot B (1963) New methods in statistical economics. Journal of political economy 71(5):421-440

Mishra PK, Das J, Mishra SK (2010) Gold price volatility and stock market returns in india. American Journal of Scientific Research 9(9):47-55

Nelson DB (1991) Conditional heteroskedasticity in asset returns: A new approach. Econometrica: Journal of the Econometric Society pp 347-370

Quandt RE (1958) The estimation of the parameters of a linear regression system obeying two separate regimes. Journal of the american statistical association 53(284):873-880

Yang SY, Doong SC (2004) Price and volatility spillovers between stock prices and exchange rates: empirical evidence from the g-7 countries. International Journal of Business and Economics 3(2):139

Zapatero F (1995) Equilibrium asset prices and exchange rates. Journal of Economic Dynamics and Control 19(4):787-811

Zivkov D, Njegic J, Milenkovic I (2015) Bidirectional volatility spillover effect between the exchange rate and stocks in the presence of structural breaks in selected eastern european economies. Finance a Uver 65(6):477

\section{Appendix}

A1-Volatility spillover between the stock market and currency market with control variable

\begin{tabular}{|c|c|c|c|c|c|}
\hline \multicolumn{3}{|c|}{$\mathrm{KSE} \rightarrow \mathrm{EXR}$} & \multicolumn{3}{|c|}{$\mathrm{EXR} \rightarrow \mathrm{KSE}$} \\
\hline \multicolumn{3}{|c|}{ Dependent Variable: LEXR } & \multicolumn{3}{|c|}{ Dependent Variable: LKSE } \\
\hline Variable & Coefficient & Z-Value & Variable & Coefficient & Z-Value \\
\hline$C$ & $0.004^{* * *}$ & -68.21 & $C$ & -0.0008 & $(-1.16)$ \\
\hline$L E X R(-1)$ & $0.132^{* * *}$ & -9.87 & $L K S E(-1)$ & $0.1096^{* * *}$ & -6.84 \\
\hline$L E X R(-2)$ & $-0.039 * * *$ & $(-4.39)$ & $L K S E(-2)$ & $0.0258^{*}$ & -1.83 \\
\hline $\operatorname{LEXR}(-3)$ & $-0.049^{* * *}$ & $(-4.44)$ & $L O P$ & 0.0048 & -0.95 \\
\hline$L G P$ & $0.002^{* * *}$ & -3.68 & $L G P(-1)$ & 0.0137 & -1.53 \\
\hline$L G P(-1)$ & $0.002^{* * *}$ & -3.23 & $L G P(-2)$ & $0.0186 *$ & -1.81 \\
\hline$L G P(-2)$ & 0.001 & -1.28 & $L G P(-3)$ & 0.009 & -0.86 \\
\hline$L G P(-3)$ & -0.001 & $(-0.73)$ & $G E X R_{D U M 1}$ & $0.0027 * *$ & -2.4 \\
\hline$R K S E_{D U M 1}$ & $-0.0039 * * *$ & $(-68.04)$ & $G E X R_{D U M 2}$ & 0.0003 & -0.42 \\
\hline$R K S E_{D U M 2}$ & $0.0002^{* * *}$ & -2.8 & $G E X R_{D U M 3}$ & $0.0005^{* *}$ & -2.38 \\
\hline \multirow{2}{*}{$R K S E_{D U M 3}$} & $0.0002^{* *}$ & -2.43 & $G E X R_{D U M 4}$ & $-0.0009 * * *$ & $(-3.01)$ \\
\hline & & & $G E X R_{D U M 5}$ & -0.0012 & $(-1.10)$ \\
\hline \multicolumn{3}{|c|}{ Variance Equation } & \multicolumn{3}{|c|}{ Variance Equation } \\
\hline$\omega$ & $-0.0479 * * *$ & $(-7.24)$ & $\omega$ & $-0.7947 * * *$ & $(-6.72)$ \\
\hline$\gamma_{1}$ & $0.9997^{* * *}$ & -2879.26 & $\gamma_{1}$ & $0.9036^{* * *}$ & -7.18 \\
\hline$\rho_{1}$ & $0.8121^{* * *}$ & -100.53 & $\gamma_{2}$ & 0.028 & -0.24 \\
\hline$\rho_{2}$ & $-0.6244^{* * *}$ & $(-79.78)$ & $\rho_{1}$ & $0.4512^{* * *}$ & -22.89 \\
\hline$\theta$ & -0.0011 & -0.45 & $\rho_{2}$ & $-0.1092^{* * *}$ & $(-2.59)$ \\
\hline \multirow[t]{2}{*}{$\pi$} & $0.0084^{* * *}$ & -8.91 & $\theta$ & $-0.0792 * * *$ & $(-6.57)$ \\
\hline & & & $\pi$ & $0.0058^{* * *}$ & -2.62 \\
\hline Observations & 4974 & & Observations & 4674 & \\
\hline SBIC & -9.886 & & SBIC & -6.041 & \\
\hline SSR & 0.0832 & & SSR & 1.0152 & \\
\hline
\end{tabular}

Note: $* * * * *$, and $*$ indicate significance at $1 \%, 5 \%$, and $10 \%$ level of significance, respectively. Here LOP and LGP represent the oil prices and gold prices, respectively.

Business Review: (2021) 16(1):1-12 
M. Jamil and H. Mobeen

A2-Volatility spillover between the stock market and currency market (Robust analysis without control variables)

\begin{tabular}{|c|c|c|c|c|c|}
\hline \multicolumn{3}{|l|}{$\mathrm{KSE} \rightarrow \mathrm{EXR}$} & \multicolumn{3}{|l|}{$\mathrm{EXR} \rightarrow \mathrm{KSE}$} \\
\hline \multicolumn{3}{|c|}{ Dependent Variable: LEXR } & \multicolumn{3}{|c|}{ Dependent Variable: LKSE } \\
\hline Variable & Coefficient & Z-Value & Variable & Coefficient & Z-Value \\
\hline$C$ & $0.0047^{* * *}$ & -62.35 & $C$ & $-0.0023 * * *$ & $(-4.20)$ \\
\hline$R E X R(-1)$ & $0.1377^{* * *}$ & -11.09 & $R K S E(-1)$ & $0.1167^{* * *}$ & -14.81 \\
\hline$R E X R(-2)$ & $-0.0389^{* * *}$ & $(-4.64)$ & $R K S E(-2)$ & $0.0475^{* * *}$ & -5.65 \\
\hline$R E X R(-3)$ & $-0.0606^{* * *}$ & $(-6.56)$ & $R E X R_{D U M 1}$ & $0.0030^{* * *}$ & -3.87 \\
\hline$R K S E_{D U M 1}$ & $-0.0046^{* * *}$ & $(-62.15)$ & $R E X R_{D U M 2}$ & -0.0002 & $(-0.33)$ \\
\hline$R K S E_{D U M 2}$ & $0.0002^{* * *}$ & -5.43 & $R E X R_{D U M 3}$ & -0.0001 & $(-0.19)$ \\
\hline \multirow{2}{*}{$R K S E_{D U M 3}$} & $-0.0005^{* * *}$ & $(-12.84)$ & $R E X R_{D U M 4}$ & 0.0001 & -0.09 \\
\hline & & & $R E X R_{D U M 5}$ & 0.0002 & -0.19 \\
\hline \multicolumn{3}{|c|}{ Variance Equation } & \multicolumn{3}{|c|}{ Variance Equation } \\
\hline$\omega$ & $-0.0341^{* * *}$ & $(-6.09)$ & $\omega$ & $-8.5266^{* *}$ & $(-2.11)$ \\
\hline$\gamma_{1}$ & $0.9995^{* * *}$ & -3301 & $\gamma_{1}$ & 0.01 & -0.02 \\
\hline$\rho_{1}$ & $0.8355^{* * *}$ & -106 & $\rho_{1}$ & 0.01 & -1.12 \\
\hline$\rho_{2}$ & $0.6669 * * *$ & $(-85.41)$ & $\rho_{2}$ & $0.0100^{* *}$ & -1.16 \\
\hline$\theta$ & $0.0194 * * *$ & -8.55 & $\theta$ & 0.01 & -2.1 \\
\hline$\pi$ & $0.0090^{* * *}$ & -10.89 & $\pi$ & 0 & 0 \\
\hline Observations & 5146 & & Observations & 5146 & \\
\hline SBIC & -9.93 & & SBIC & -5.67 & \\
\hline SSR & 0.0851 & & SSR & 1.0198 & \\
\hline
\end{tabular}

Note: ${ }^{* * *},{ }^{* *}$, and $*$ indicate significance at $1 \%, 5 \%$, and $10 \%$ level of significance, respectively. 